\title{
Opening the Language Lab
}

\author{
by Courtenay S. Chadwell
}

M.A., TEFL.

The traditional language laboratory, with a central monitoring station and rows of booths containing earphones, (can be one of the most tedious aspects of foreign language learning. Even the most avid language student is filled with boredom in the clutches of the lab. Too many students spend too many hours slumped in the booths, thinking of something other than the material they are supposed to be practicing, doing assignments for other classes, or sleeping, but managing to produce rote utterances in the event the monitor is listening. The mechanical atmosphere soon loses its intrigue. The lack of personal contact has a deadening effect on the motivation of most students.

The traditional system may serve a function in an area where the target language is not spoken. It is then a means of oral practice which the learner would not otherwise have, and provided the student has the will to use it earnestly, it is helpful. In an area where the target language is spoken, however, 1 believe it serves little or no function. In this situation, the student can be encouraged or required to practice speaking with native speakers outside of class. This type of activity is closer to communication, which is, after all, our objective. Oral drill work, that which the traditional lab offers, should be done in class. It is the application of this work to a communicative activity that we should emphasize.

The time and expense spent on the traditional laboratory could be applied to an alternative system that would stimulate, rather than deaden, the students' interest in the language. The laboratory I have designed is based on the open classroom model. This system can be used by any age level, from preschool to college and adult, and by any language level or combined levels. It can also accommodate a heterolingual group. And it is possible to implement at less expense than the traditional lab.

As with any open classroom, there are various stations which the students visit. The younger the students, the more visually interesting the stations should be. In this design there are six stations; some of these could be combined and/or others added. Below is a floor plan; let's take a tour.

We first come to the Listening Comprehension \& Pronunciation Station. Tapes are essential for this station. Listening comprehension tapes include minimal pairs and minimal sentences. For more advanced students there are taped anecdotes, paragraphs and lectures, the comprehension of which must be demonstrated in either written or spoken form. Pronunciation tapes produce utterances for the students to mimic. The type of tape which allows for student response (which can be taped over without 
erasing the model) allows the students' work to be checked later. A Language Master ${ }^{\circledR}$ is very helpful for pronunciation and listening comprehension practice. Written words, sentences and paragraphs can also be used for pronunciation work; blank tapes should be provided for this type of practice, so the students, as well as the teacher, can listen and check their pronunciation.

The Conversation Station is arranged to accommodate practice by a single student, or by a pair or small group. Alone, a student can talk about one of the set of pictures, or choose one of the suggested impromptu speech topics. Or s/he can work with a tape which contains one voice of a telephone conversation or an interview. A pair or group of students can choose a card presenting a situation to be role-played. Or they can finish the beginning of a conversation, as presented on tape or on a card. They can debate an issue, or interview each other. All practice at this station should be taped for later listening.

The Grammar Station is much like traditional language lab work. There are taped exercises, repetition, substitution and transformation drills, to practice that which has been presented previously in class. In addition, there are written exercises to review class work.

The Reading Station contains two sections. One section is concerned with reading skills. Given short readings, the students complete written exercises which test comprehension, grasp of the central idea, and speed. For beginning students, pictures are used to test comprehension. The other section is a library. All students are encouraged to do some free reading each week. A period of time is designated for reading. Books at appropriate levels, magazines, newspapers, and comics have been collected for the library.

At the Composition Station there are different types of exercises for different levels of proficiency. For young students, or those for whom the target writing system is new, there are handwriting exercises. For intermediate students there are controlled composition exercises (such as changing a paragraph from third person to first, or from present to past tense). For more advanced students there are story starters pictures to be described, letters to be answered, and ideas for business letters to be written. There are also paragraph-writing exercises, and ideas for themes and essays.

Our final stop is the Vocabulary Station. Here there are word building exercises, practicing affixes and root meanings. There are exercises and games to practice antonyms and synonyms. Definition exercises differ according to level: lower-level students can identify pictures, or choose the correct description of what is happening in a picture; higherlevel students can determine a definition from a word's context. There are also games at this station - word games, such as crossword puzzles and jumbled words, and board games, such as Scrabble, Probe, etc. And there are dictionaries and thesauri. 
These six stations cover what I consider to be basic needs of a foreign or second language program. As I mentioned earlier, some of these stations could be combined or redefined. A teacher might feel more comfortable combining reading and vocabulary, and want a separate Games Station. Other stations could be added. For example, a CrossCultural Station or a Study Skills Station might be desired. Or a Newspaper Station would be helpful at a school publishing a student newspaper. There are also many more possibilities for materials, which can be made or purchased.

Once the stations are defined and the materials for each obtained, an operational system must be established. I have found the following system to work well.

On the first day, each student is given a folder for completed exercises. A record sheet, also kept in the folder, allows space for the date, station, exercise(s) completed, and points given for each exercise. Two points are given for each exercise done well, one point for each done poorly.

In most classrooms, the teacher needs to set up some guidelines. I required that each station be visited each week. Once an exercise is completed at each station, the students may choose any activity they like. The required stations may be visited in any order the students wish. (Limited equipment would perhaps necessitate a schedule for certain stations.) Some teachers may wish to control which exercises are done by students at each station. I have found that the suggestion that a certain exercise is too easy or too difficult (usually the former) is sufficient guidance. In determining the minimum amount of weekly work, it is essential that slower students be given enough time to complete the basic requirement. Faster students will have time to use on extra work.

Students may receive requests from any of their regular class teachers to do certain exercises at particular stations. This allows the lab time to be used for necessary review or extra practice by those who need it. A teacher may then request that a homework assignment be rewritten at, say, the Grammar Station.

For an extra bit of variety, a "Special of the Week" activity may be required. This may be accomplished in place of one of the stations, or, provided all students can handle it, in addition. I have compiled entire newspaper issues using "Weekly Special" material.

At the end of the term, the students are evaluated according to the number of points they have accumulated throughout the term. A curve will simulate competition, but it tends to penalize the slow, thorough students. An alternate system is a B grade given for completion of the required exercises (well done); extra work is required for an $A$.

This model is more sensible than the traditional language lab in several ways. Like the latter, it is individualized. Students may work at their own levels; they may review material they did not fully grasp in 
class or work on material more difficult than that done in class. The teacher is free to roam from student to student, making suggestions and offering help.

Unlike the traditional lab, the open-classroom model strengthens independent work. This lab is student-centered rather than teachercentered. Freedom to choose exercises and/or the order in which they are done encourages students to see learning and studying as their own responsibility. This is particularly important for students intending to enter American colleges or universities, where independent study is becoming more and more common.

Unlike the traditional lab, which allows the students to practice only speaking and listening, this lab allows them to work on all language skills. This aspect is pertinent to any language-learning situation, but especially to language programs in countries where the target language is spoken. Students have more opportunity to practice speaking outside of class. The lab time can be used for any area in which they need more work, as well as general support for all language skills.

And most unlike the traditional lab, this system is stimulating and interesting. It offers a variety of activities to develop a variety of skills. It offers flexibility in class procedures. It allows movement. And it allows personal, human contact between teacher and student on a one-to-one basis. With today's crowded classrooms, a more humanized environment, rather than a more mechanized one, is certainly in order.

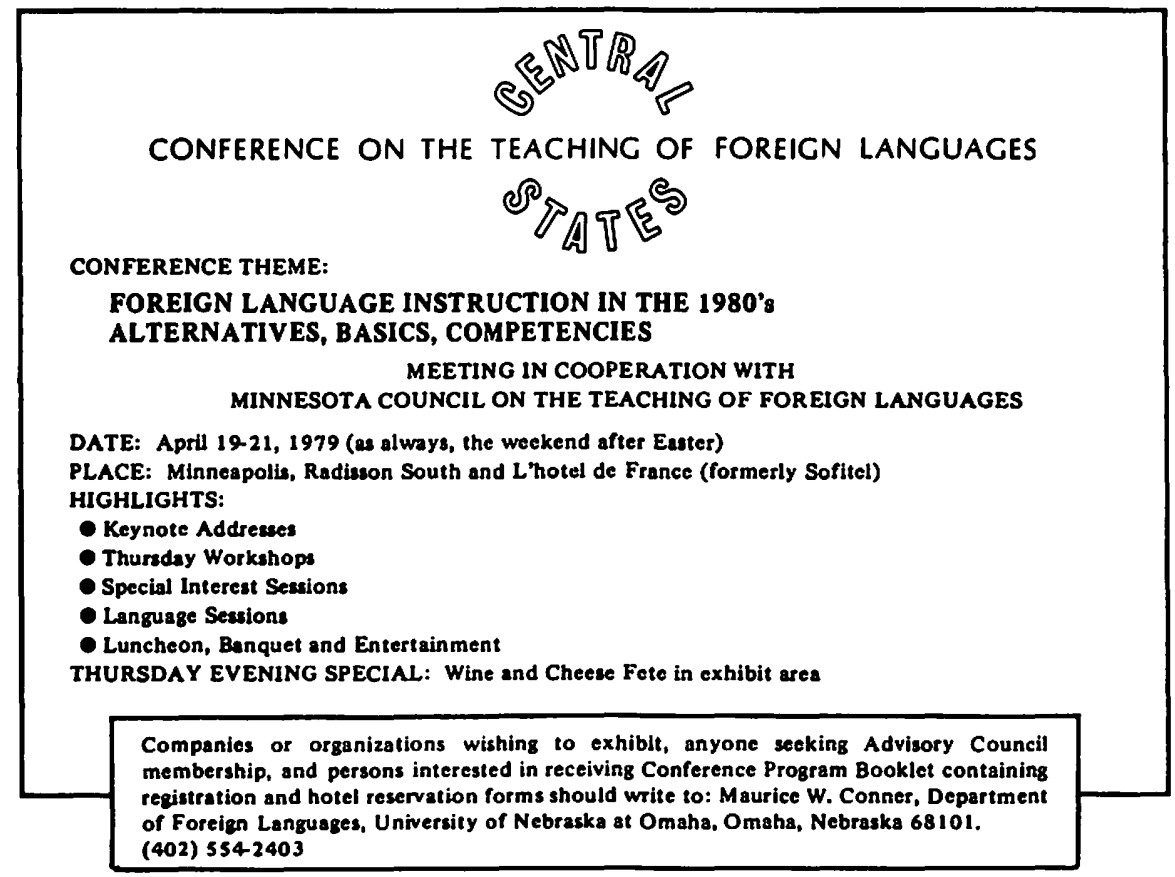

